\title{
Estradiol affects liver mitochondrial function in ovariectomized and tamoxifen-treated ovariectomized female rats
}

\author{
Paula I. Moreira ${ }^{\mathrm{a}, \mathrm{b}}$, José B.A. Custódio ${ }^{\mathrm{a}, \mathrm{c}}$, Elsa Nunes ${ }^{\mathrm{a}, \mathrm{b}}$, António Moreno ${ }^{\mathrm{a}, \mathrm{d}, \mathrm{e}}$, Raquel Seiça ${ }^{\mathrm{a}, \mathrm{b}}$, \\ Catarina R. Oliveira ${ }^{\mathrm{a}, \mathrm{f}}$, Maria S. Santos ${ }^{\mathrm{a}, \mathrm{d}, *}$ \\ ${ }^{a}$ Center for Neuroscience and Cell Biology, University of Coimbra, 3005-504 Coimbra, Portugal \\ ${ }^{\mathrm{b}}$ Institute of Physiology, Faculty of Medicine, University of Coimbra, 3005-504 Coimbra, Portugal \\ ${ }^{\mathrm{c}}$ Institute of Biochemistry, Faculty of Pharmacy, University of Coimbra, 3005-504 Coimbra, Portugal \\ d Department of Zoology, Faculty of Sciences and Technology, University of Coimbra, 3005-504 Coimbra, Portugal \\ ${ }^{\mathrm{e}}$ Institute of Marine Research, University of Coimbra, 3005-504 Coimbra, Portugal \\ ${ }^{\mathrm{f}}$ Institute of Biochemistry, Faculty of Medicine, University of Coimbra, 3005-504 Coimbra, Portugal
}

Received 27 November 2006; revised 6 February 2007; accepted 9 February 2007

Available online 23 February 2007

\begin{abstract}
Given the tremendous importance of mitochondria to basic cellular functions as well as the critical role of mitochondrial impairment in a vast number of disorders, a compelling question is whether $17 \beta$-estradiol (E2) modulates mitochondrial function. To answer this question we exposed isolated liver mitochondria to E2. Three groups of rat females were used: control, ovariectomized and ovariectomized treated with tamoxifen. Tamoxifen has antiestrogenic effects in the breast tissue and is the standard endocrine treatment for women with breast cancer. However, under certain circumstances and in certain tissues, tamoxifen can also exert estrogenic agonist properties. We observed that at basal conditions, ovariectomy and tamoxifen treatment do not induce any statistical alteration in oxidative phosphorylation system and respiratory chain parameters. Furthermore, tamoxifen treatment increases the capacity of mitochondria to accumulate $\mathrm{Ca}^{2+}$ delaying the opening of the permeability transition pore. The presence of $25 \mu \mathrm{M}$ E2 impairs respiration and oxidative phosphorylation system these effects being similar in all groups of animals studied. Curiously, E2 protects against lipid peroxidation and increases the production of $\mathrm{H}_{2} \mathrm{O}_{2}$ in energized mitochondria of control females. Our results indicate that $\mathrm{E} 2$ has in general deleterious effects that lead to mitochondrial impairment. Since mitochondrial dysfunction is a triggering event of cell degeneration and death, the use of exogenous E2 must be carefully considered.
\end{abstract}

(C) 2007 Elsevier Inc. All rights reserved.

Keywords: 17ß-Estradiol; Mitochondria; Oxidative phosphorylation system; Ovariectomy; Oxidative stress; Respiratory chain; Tamoxifen

\section{Introduction}

Breast cancer is the most frequently diagnosed and the second cause of cancer death in women, thus making breast cancer a most feared disease. Despite the high incidence, breast cancer mortality is decreasing and one of the main contributory factors to this marked improvement in survival has been the more widespread use of systemic therapy in early-stage disease. For women with hormone-sensitive cancer, this involves

\footnotetext{
* Corresponding author. Department of Zoology, Faculty of Sciences and Technology, University of Coimbra, 3004-517 Coimbra, Portugal. Fax. +351 239826798.

E-mail address: mssantos@ci.uc.pt (M.S. Santos).
}

adjuvant endocrine therapy that reduces estrogen synthesis (i.e. ovarian suppression in premenopausal women or aromatase inhibitors in postmenopausal women) or estrogen activity (by using antiestrogenic compounds, irrespective of menopausal status) (Kwan et al., 2005). However, many women experience health and quality-of-life problems related to estrogen deficiency as a result. To circumvent this problem, hormone replacement therapy (HRT), which includes both estrogen and/ or progestin, has been administered to postmenopausal women. Although the safety of HRT has been questioned in breast cancer survivors, it has been shown that HRT may be safe in women with receptor-negative or receptor-positive cancers in the presence of tamoxifen (TAM) (Kwan et al., 2005). Indeed, the synthetic nonsteroidal antiestrogen drug TAM is widely 
used in the chemotherapy of breast cancer (Richardson, 1988) and has been proposed as a prophylactic agent against this disease. TAM undergoes extensive hepatic metabolism being 4-hydroxytamoxifen (OHTAM) and endoxifen its major active metabolites and responsible for its antiestrogenic activity (Lim et al., 2006). However, it is now known that under certain circumstances and in certain tissues, in addition to acting as competitive inhibitors of endogenous estrogen, estrogen antagonists can also exert estrogenic agonist properties (Katzenellenbogen et al., 1996; Sato et al., 1996; McDonnell, 2000).

Mitochondria play a central role in both cell life and death (Duchen, 2004). Mitochondria are essential for the production of ATP through oxidative phosphorylation, regulate intracellular $\mathrm{Ca}^{2+}$ homeostasis and are the principal generators of intracellular reactive oxygen species (ROS). Furthermore, mitochondria also play a key role in controlling pathways that lead to apoptosis. Defects of mitochondrial function can result in excessive production of ROS, formation of the permeability transition pore (PTP) and the release of small proteins that trigger apoptosis. Therefore, changes in the structural and functional characteristics of mitochondria provide a number of primary targets for drugs-induced toxicity and cell death (Wallace and Starkov, 2000). Indeed, accumulating evidence indicates that both 17ß-estradiol (E2) (Zheng and Ramirez, 1999; Yang et al., 2004) and TAM (Custodio et al., 1998; Moreira et al., 2004,2005) modulate mitochondrial function.

The aim of this study was the evaluation of the impact of E2 on liver mitochondria isolated from control, ovariectomized (mimicking a menopausal state/absence of estrogen) and TAMtreated ovariectomized (mimicking a breast cancer therapy) female rats. To achieve our goal, we evaluated several mitochondrial parameters from the respiratory chain (states 3 and 4 of respiration, respiratory control ratio (RCR) and FCCPstimulated respiration), oxidative phosphorylation system (transmembranar, depolarization induced by ADP and lag phase), lipid peroxidation parameters (TBARS levels and oxygen consumption), the capacity of mitochondria to produce hydrogen peroxide $\left(\mathrm{H}_{2} \mathrm{O}_{2}\right)$, and the susceptibility of mitochondria to permeability transition pore (PTP) opening.

\section{Methods}

Chemicals. $\quad 17 \beta$-Estradiol (E2), 4-(2-hydroxymethyl)-1-piperazineethanesulfonic acid (Hepes), cyclosporin A (CsA), oligomycin, ethylene glycol-bis ( $\beta$-aminoethylether) $N N N^{\prime} N^{\prime}$-tetraacetic acid (EGTA), tetraphenylphosphonium $\left(\mathrm{TPP}^{+}\right)$were obtained from Sigma Chemical Co and TAM pellets $(5 \mathrm{mg}$ per pellet, $21 \mathrm{~d}$ release) from Innovative Research of America, Sarasota, FL. All the other chemicals were of the highest grade of purity commercially available.

Animals, ovariectomy, and tamoxifen treatment. Female rats (12-15 weeks) from our animal colony (Laboratory Research Center, University Hospital) were housed five per cage with ad libitum access to food (URF1-Charles River, France) and water and maintained at a constant temperature and humidity with a $12 \mathrm{~h} \mathrm{light/dark} \mathrm{cycle.} \mathrm{To} \mathrm{remove} \mathrm{the} \mathrm{main} \mathrm{source} \mathrm{of} \mathrm{female} \mathrm{hormones,} \mathrm{the}$ animals were bilaterally ovariectomized under anesthesia (i.m.) using ketamine chloride $(88.5 \mathrm{mg} / \mathrm{kg}$, Park Davies, USA) and chlorpromazine chloride $(2.65 \mathrm{mg} / \mathrm{kg}$, Lab. Victoria, Portugal). One week after ovariectomy, pellets containing placebo (OVX females) or TAM ( $5 \mathrm{mg}$ per pellet, $21 \mathrm{~d}$ release) (TAM females) that steadily release approximately $0.8 \mathrm{mg} / \mathrm{kg} / \mathrm{day}$ animals, were implanted in the neck of the animals. Additionally, one group of animals was neither ovariectomized nor implanted (control females). Biochemical analyses of blood samples collected from cardiac puncture were performed with commercial Kits used in the Clinical Laboratory of our University Hospital.

Mitochondria preparation. $\quad 21$ days after the implant of pellets, animals were euthanized by cervical displacement and decapitation, following procedures approved by the Institutional Animal Care and Use Committee. Mitochondria were isolated by conventional methods (Gazotti et al., 1979), with slight modifications. Briefly, liver mitochondria were isolated in a medium containing $250 \mathrm{mM}$ sucrose, $5 \mathrm{mM}$ Hepes, $0.5 \mathrm{mM}$ EGTA and $0.1 \%$ defatted bovine serum albumin ( $\mathrm{pH}$ 7.2). EGTA and bovine serum albumin were omitted from the final washing medium. The mitochondrial pellet was washed twice, and suspended in the washing medium.

Mitochondrial protein was determined by the biuret method calibrated with bovine serum albumin (Gornall et al., 1949).

We used liver mitochondria as experimental model for three main reasons: 1) TAM is extensively metabolized in the liver to give the active metabolites 4-OHTAM and 4-hydroxy- $N$-desmethyltamoxifen (endoxifen), which have a greater anti-estrogenic activity than TAM (Fromson et al., 1973; Lim et al., 2006); 2) the metabolism of estrogens mainly occurs in liver (Tsuchiya et al., 2005) and 3) mitochondria control steroidogenesis (Felty and Roy, 2005).

Mitochondrial respiration. Oxygen consumption of isolated mitochondria was monitored polarographically with a Clark oxygen electrode (Estabrook, 1967) connected to a suitable recorder in a thermostated water-jacketed closed chamber with magnetic stirring. The reactions were carried out at $30^{\circ} \mathrm{C}$ in $1 \mathrm{ml}$ of standard respiratory medium (130 mM sucrose, $50 \mathrm{mM} \mathrm{KCl}, 2.5 \mathrm{mM} \mathrm{MgCl}_{2}$, $2.5 \mathrm{mM} \mathrm{KH}_{2} \mathrm{PO}_{4}, 5 \mathrm{mM}$ Hepes and $0.1 \mathrm{mM} \mathrm{EGTA}$ ) with $1 \mathrm{mg}$ of protein. E2 was incubated with isolates $1 \mathrm{~min}$ before substrate addition. States 4 and 3 respiration were initiated with $5 \mathrm{mM}$ glutamate $/ 2.5 \mathrm{mM}$ malate and ADP $(150 \mathrm{nmol} / \mathrm{mg}$ protein), respectively. Respiration rates were calculated assuming an oxygen concentration of $240 \mathrm{nmol} \mathrm{O}_{2} / \mathrm{ml}$ in the experimental medium at $30{ }^{\circ} \mathrm{C}$. States 3 and 4 and respiratory control ratio $(\mathrm{RCR}=$ state $3 /$ state 4$)$ were calculated according to Chance and Williams (1956). FCCP-stimulated respiration was induced with the addition of $1 \mu \mathrm{M}$ FCCP added 2 min after mitochondria energization.

Membrane potential $\left(\Delta \Psi_{m}\right)$. The mitochondrial transmembrane potential $\left(\Delta \Psi_{\mathrm{m}}\right)$ was monitored by evaluating transmembrane distribution of the lipophilic cation $\mathrm{TPP}^{+}$(tetraphenylphosphonium) with a $\mathrm{TPP}^{+}$-selective electrode prepared according to Kamo et al. (1979) using a $\mathrm{Ag} / \mathrm{AgCl}_{2}$-saturated electrode as reference (model MI 402; Microelectrodes, Inc., Bedford, NH). TPP ${ }^{+}$uptake has been measured from the decreased $\mathrm{TPP}^{+}$concentration in the medium sensed by the electrode. The potential difference between the selective electrode and the reference electrode was measured with an electrometer and recorded continuously in a Linear 1200 recorder. The voltage response of the $\mathrm{TPP}^{+}$electrode to $\log \left[\mathrm{TPP}^{+}\right]$was linear with a slope of $59 \pm 1$, in a good agreement with the Nernst equation. Reactions were carried out in a chamber with magnetic stirring in $1 \mathrm{ml}$ of the standard medium ( $130 \mathrm{mM}$ sucrose, $50 \mathrm{mM} \mathrm{KCl}, 2.5 \mathrm{mM} \mathrm{MgCl}_{2}$, $2.5 \mathrm{mM} \mathrm{KH}_{2} \mathrm{PO}_{4}, 100 \mu \mathrm{M}$ EGTA, $5 \mathrm{mM}$ Hepes, $\mathrm{pH}$ 7.4) containing $3 \mu \mathrm{M} \mathrm{TPP}^{+}$. This $\mathrm{TPP}^{+}$concentration was chosen in order to achieve high sensitivity in measurements and to avoid possible toxic effects on mitochondria (Wingrove and Gunter, 1986). The $\Delta \Psi_{\mathrm{m}}$ was estimated by the equation:

$\Delta \Psi_{\mathrm{m}}(\mathrm{mV})=59 \log (v / V)-59 \log \left(10^{\Delta E / 59}-1\right)$,

as indicated by Kamo et al. (1979) and Muratsugu et al. (1977). $v, V$, and $\Delta E$ stand for mitochondrial volume, volume of the incubation medium, and deflection of the electrode potential from the baseline, respectively. This equation was derived assuming that $\mathrm{TPP}^{+}$distribution between the mitochondria and the medium follows the Nernst equation and that the law of mass conservation is applicable. A matrix volume of $1.1 \mu \mathrm{l} / \mathrm{mg}$ protein was assumed. No correction was made for the "passive" binding contribution of $\mathrm{TPP}^{+}$to the mitochondrial membranes because the purpose of the experiments was to show relative changes in potentials rather than absolute values. As a consequence, we can anticipate a slight overestimation on $\Delta \Psi_{\mathrm{m}}$ values. However, the overestimation is only significant at $\Delta \Psi_{\mathrm{m}}$ values below $90 \mathrm{mV}$, therefore, far from our measurements. 
Mitochondria $(1 \mathrm{mg} / \mathrm{ml})$ in the standard respiratory medium supplemented with $3 \mu \mathrm{M} \mathrm{TPP}^{+}$were energized by the addition of $5 \mathrm{mM}$ glutamate $/ 2.5 \mathrm{mM}$ malate. After a steady-state distribution of $\mathrm{TPP}^{+}$had been reached (ca. 1 min of recording) $\mathrm{ADP}$ was added and $\Delta \Psi_{\mathrm{m}}$ fluctuations recorded. E2 was preincubated $1 \mathrm{~min}$ prior mitochondria energization.

Measurements of mitochondrial permeability transition pore (PTP). Oxygen uptake associated to PTP induction was measured as described above, except that in this case, mitochondria $(1 \mathrm{mg} / \mathrm{ml})$ were suspended in a reaction medium containing $200 \mathrm{mM}$ sucrose, $10 \mathrm{mM}$ Tris-Mops, $1 \mathrm{mM} \mathrm{KH}_{2} \mathrm{PO}_{4}, 10 \mu \mathrm{M}$ EGTA, $2 \mu \mathrm{M}$ rotenone and $0.5 \mu \mathrm{g}$ oligomycin $/ \mathrm{ml}, \mathrm{pH} 7.4$, at $30{ }^{\circ} \mathrm{C}$ and energized with succinate. Opening of the pore was induced by $\mathrm{Ca}^{2+}$ addition $(70 \mathrm{nmol} / \mathrm{mg}$ protein) after mitochondria energization and prevented by preincubation with CsA $(0.85 \mu \mathrm{M})$. E2 was incubated with mitochondria $1 \mathrm{~min}$ before energization with succinate.

Mitochondrial $\mathrm{Ca}^{2+}$ fluxes were measured by monitoring the changes in $\mathrm{Ca}^{2+}$ concentration in the reaction medium using the hexapotassium salt of the fluorescence probe Calcium Green 5-N (Rajdev and Reynolds, 1993). Mitochondria $(0.5 \mathrm{mg})$ were resuspended in $2 \mathrm{ml}$ of reaction medium supplemented with $100 \mathrm{nM}$ of Calcium Green 5-N followed by addition of $\mathrm{Ca}^{2+}(70 \mathrm{nmol} / \mathrm{mg}$ protein) and energization with succinate $(5 \mathrm{mM})$. Fluorescence was recorded continuously in a water-jacketed cuvette holder at $30{ }^{\circ} \mathrm{C}$ using a Perkin-Elmer spectrofluorometer LS-50 B with an excitation wavelength of $506 \mathrm{~nm}$ (slit $4 \mathrm{~nm}$ ) and an emission wavelength of $532 \mathrm{~nm}$ (slit $6 \mathrm{~nm}$ ).

Evaluation of oxidative stress. The extent of lipid peroxidation was evaluated by oxygen consumption monitored polarographically at $30{ }^{\circ} \mathrm{C}$ using a Clarktype oxygen electrode (YSI Model 5331, Yellow Springs Inst) placed in a glass chamber equipped with magnetic stirring (Santos et al., 2001). Reactions were carried out in $1 \mathrm{ml}$ of reaction medium containing $175 \mathrm{mM} \mathrm{HCl}, 10 \mathrm{mM}$ Tris$\mathrm{HCl}, \mathrm{pH} 7.4$ and $1 \mathrm{mg} / \mathrm{ml}$ of protein. Reactions were started by the addition of $1 \mathrm{mM} \mathrm{ADP} / 0.1 \mathrm{Fe}^{2+}$ and the changes in oxygen tension calculated assuming a concentration of $240 \mathrm{nmol} \mathrm{O}_{2} / \mathrm{ml}$. E2 was incubated with mitochondria for $1 \mathrm{~min}$ before the addition of $\mathrm{ADP} / \mathrm{Fe}^{2+}$. In parallel, the extent of lipid peroxidation was also determined by measuring thiobarbituric acid reactive substances (TBARS), using the thiobarbituric acid assay, according to a modified procedure as described elsewhere (Santos et al., 2001). The amount of TBARS formed was calculated using a molar extinction coefficient of $1.56 \times 10^{5} \mathrm{M}^{-1} \mathrm{~cm}^{-1}$ and expressed as nmol TBARS/mg protein.

The rate of $\mathrm{H}_{2} \mathrm{O}_{2}$ production in isolated mitochondria was determined fluorimetrically using a modification of the method described by Barja (1999). Briefly, mitochondria were incubated at $30{ }^{\circ} \mathrm{C}$ with $5 \mathrm{mM}$ glutamate $/ 2.5 \mathrm{mM}$ malate in $1.5 \mathrm{ml}$ of phosphate buffer, $\mathrm{pH} 7.4$, containing $0.1 \mathrm{mM}$ EGTA, $5 \mathrm{mM}$ $\mathrm{KH}_{2} \mathrm{PO}_{4}, 3 \mathrm{mM} \mathrm{MgCl}, 145 \mathrm{mM} \mathrm{KCl}, 30 \mathrm{mM}$ Hepes, $0.1 \mathrm{mM}$ homovanillic acid and $6 \mathrm{U} / \mathrm{ml}$ horseradish peroxidase in the presence or absence of E2 as described above. The incubation was stopped at $10 \mathrm{~min}$ with $0.5 \mathrm{ml}$ of cold $2 \mathrm{M}$ glycine buffer containing $25 \mathrm{mM}$ EDTA and $\mathrm{NaOH}, \mathrm{pH} 12$. The fluorescence of supernatants was measured at $312 \mathrm{~nm}$ as excitation wavelength and $420 \mathrm{~nm}$ as emission wavelength. The rate of peroxide production was calculated using a standard curve of $\mathrm{H}_{2} \mathrm{O}_{2}$.

Statistical analysis. The results are presented as mean \pm S.E.M. of the indicated number of experiments. Statistical significance between the different assays was made using the one-way analysis of variance (ANOVA) followed by the Tukey post-test, for multiple comparisons. A $p$-value $<0.05$ was considered statistically significant.

\section{Results}

\section{Characterization of animals}

OVX females presented a significant increase in body weight when compared with control females (Table 1). However, TAM treatment avoided body weight gain (Table 1). Furthermore, we observed that total cholesterol and HDL-cholesterol were significantly increased in OVX females when compared with
Table 1

Characterization of control, OVX and TAM-treated OVX females

\begin{tabular}{lccc}
\hline & Control & OVX & TAM \\
\hline Body weight gain $(\%)$ & $18.0 \pm 1.7$ & $28.2 \pm 6.8^{*}$ & $1.5 \pm 1.5^{* *, \# \#}$ \\
RBCs count $\left(\times 10^{12} / 1\right)$ & $7.3 \pm 0.4$ & $7 \pm 0.1$ & $6.7 \pm 0.3$ \\
WBCs count $\left(\times 10^{9} / 1\right)$ & $4.1 \pm 0.3$ & $5.6 \pm 1.1$ & $5.3 \pm 0.7$ \\
PLT count $\left(\times 10^{9} / 1\right)$ & $601 \pm 210$ & $651 \pm 163$ & $730 \pm 173$ \\
AST (IU/l) & $109 \pm 2.3$ & $106 \pm 4.2$ & $138 \pm 8.5^{*, \#}$ \\
ALT (IU/l) & $43.3 \pm 3.2$ & $35.7 \pm 2.4$ & $37 \pm 1.8$ \\
ALP (IU/l) & $71.5 \pm 7.7$ & $117 \pm 7.1$ & $104 \pm 7.3^{*}$ \\
$\gamma$-GT (IU/l) & $2.8 \pm 0.6$ & $2 \pm 0.7$ & $2.4 \pm 0.5$ \\
Total cholesterol $(\mathrm{mg} / \mathrm{dl})$ & $47.3 \pm 7.9$ & $78.0 \pm 7.1^{*}$ & $67.2 \pm 11.1^{\#}$ \\
HDL cholesterol $(\mathrm{mg} / \mathrm{dl})$ & $30.2 \pm 5.6$ & $51.5 \pm 5.1^{*}$ & $39.1 \pm 7.2^{\#}$ \\
Triglycerides $(\mathrm{mg} / \mathrm{dl})$ & $135 \pm 27.4$ & $104.5 \pm 12^{*}$ & $99.8 \pm 16.3^{*}$ \\
\hline
\end{tabular}

The values are expressed as mean \pm S.E.M of five to six animals. $* * p<0.01$;

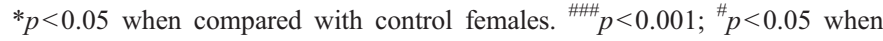
compared with OVX females.

RBCs — red blood cells; WBCs — white blood cells; PLT — platelets; ASTaspartate aminotransferase; ALT —alanine aminotransferase; ALP—alkaline phosphatase; $\gamma$-GT $-\gamma$-glutamyl transferase.

control females. Administration of TAM normalized the levels of both parameters. However, triglycerides were significantly decreased in OVX and TAM compared with controls females (Table 1). We observed also that alkaline phosphatase (ALP) and glutamate oxaloacetate transaminases (AST) were significantly higher in TAM females when compared with control females. However, no statistical differences were found in red and white blood cells and platelets count, glutamate pyruvate transaminases (ALT) and $\gamma$-glutamiltransferase $(\gamma$-GT) in the three groups of animals (Table 1).

\section{E2 impairs mitochondrial respiration the effect being more pronounced in TAM females}

We observed that at basal conditions no statistical differences were observed in states 3 and 4, RCR and FCCP-stimulated respiration in the three groups of animals studied (Fig. 1). Incubation of mitochondria with $25 \mu \mathrm{M}$ E2 induced a significant decrease in state 3 respiration, RCR and FCCPstimulated respiration in mitochondria isolated from the three groups of animals, when compared with controls at basal conditions (Figs. 1A, C and D). Furthermore, E2 also induced an increase in state 4 respiration though only statistically significant in mitochondria of TAM-treated females when compared with controls at basal conditions (Fig. 1B).

\section{E2 affects the oxidative phosphorylation system}

The mitochondrial transmembrane potential $\left(\Delta \Psi_{\mathrm{m}}\right)$ is fundamental for the phenomenon of oxidative phosphorylation, the conversion of ADP to ATP via ATP synthase. Mitochondrial respiratory chain pumps $\mathrm{H}^{+}$out of the mitochondrial matrix across the inner mitochondrial membrane. The $\mathrm{H}^{+}$gradient originates an electrochemical potential $(\Delta p)$ resulting in a $\mathrm{pH}$ $(\Delta \mathrm{pH})$ and a voltage gradient $\left(\Delta \Psi_{\mathrm{m}}\right)$ across the mitochondrial inner membrane. $\Delta \Psi_{\mathrm{m}}$ developed by mitochondria after energization with glutamate/malate was $\approx-220 \mathrm{mV}$ (negative inside) (Table 2). As Table 2 shows we did not observe any 
A
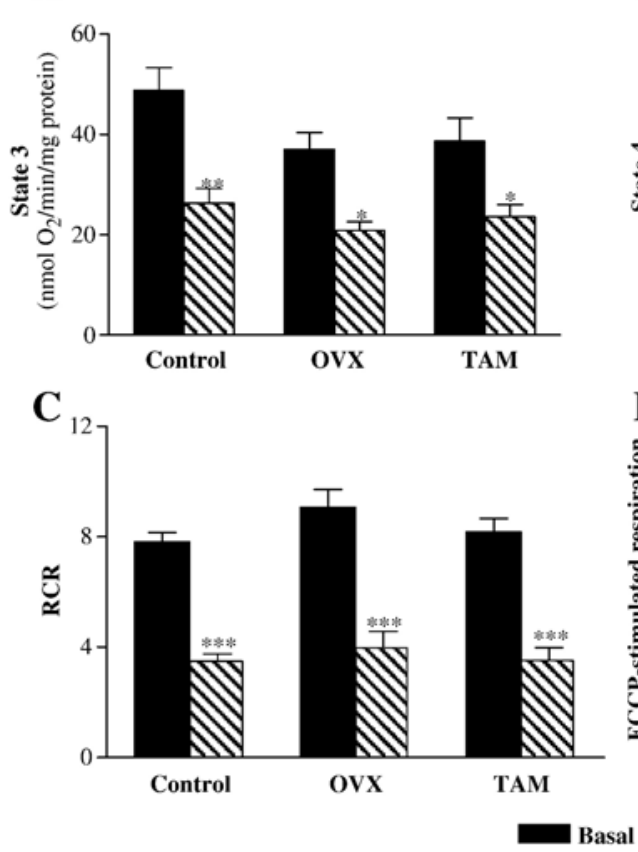

B

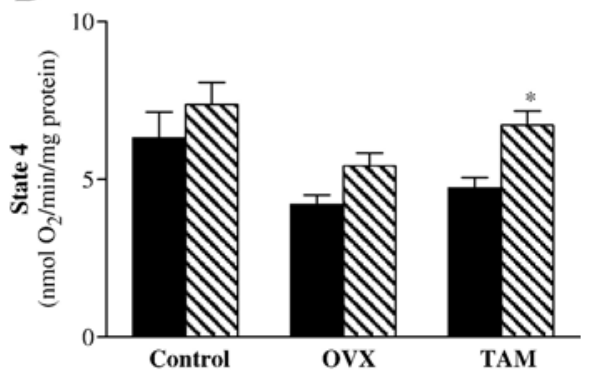

D

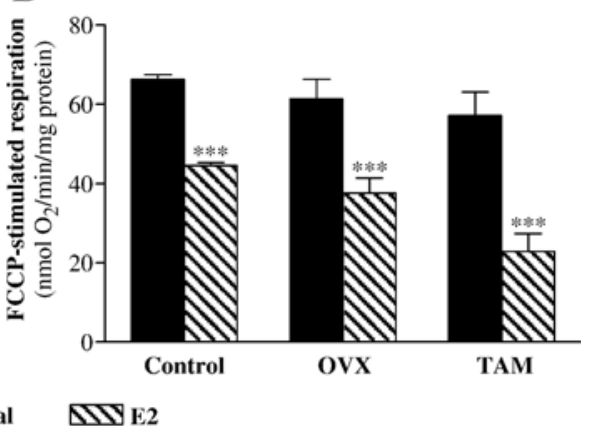

Fig. 1. Effect of 17ß-estradiol (E2) on states 3 (A) and 4 (B) of respiration, RCR (C) and FCCP-stimulated respiration (D) of mitochondria isolated from control, ovariectomized (OVX) and tamoxifen-treated ovariectomized (TAM) rat females. Freshly isolated liver mitochondria $(1 \mathrm{mg})$ in $1 \mathrm{ml}$ of the standard medium were energized with $5 \mathrm{mM}$ glutamate $/ 2.5 \mathrm{mM}$ malate. Isolates were incubated with $\mathrm{E} 2 \mathrm{for} 1 \mathrm{~min}$, at $30^{\circ} \mathrm{C}$, before mitochondria energization. ${ }^{* * *} p<0.001$; ${ }^{* *} p<0.01$; ${ }^{*} p<0.05$ when compared with the respective basal condition. Data shown represent mean \pm S.E.M. from six animals for each experimental group studied.

significant alteration in $\Delta \Psi_{\mathrm{m}}$ from mitochondria isolated from the three groups of animals at basal conditions as well as when incubated with E2. Furthermore, we observed that at basal conditions the depolarization induced by ADP and the lag phase (time necessary for ADP phosphorylation) did not alter significantly in all groups of animals tested. However, both parameters were significantly increased when mitochondria were incubated with E2 (Table 2).

\section{E2 does not interfere with PTP: protective effect of TAM}

When PTP is induced, acceleration of mitochondrial respiration and alteration of $\mathrm{Ca}^{2+}$ fluxes are commonly observed, and these changes are often used as a simple means to judge whether or not a PTP is induced. We observed that after the addition of $70 \mathrm{nmol} \mathrm{Ca}^{2+} / \mathrm{mg}$ protein, oxygen consumption is less pronounced in mitochondria isolated from TAM females (OVX+TAM) when compared with control and OVX females (Fig. 2). However, the lower consumption of oxygen occurred when mitochondria were incubated with CsA, the specific inhibitor of PTP (Fig. 2). Again, the presence of E2 did not affect significantly oxygen consumption (Fig. 2). When we measured $\mathrm{Ca}^{2+}$ fluxes, the protective effect of TAM was pronounced (Fig. 3). Indeed, we observed that isolated mitochondria from TAM females incubated with $70 \mathrm{nmol} \mathrm{Ca}{ }^{2+} / \mathrm{mg}$ protein rapidly accumulate and retained the $\mathrm{Ca}^{2+}$ from the medium this effect being similar to that exerted by CsA (Fig. 3). In contrast, mitochondria from OVX and control females accumulate $\mathrm{Ca}^{2+}$ from the medium but after some time they release the accumulated $\mathrm{Ca}^{2+}$ (Fig. 3). The drop of $\Delta \Psi_{\mathrm{m}}$ is also a typical phenomenon that leads to the induction of PTP. We observed that in energized mitochondria isolated from the three groups of animals the first and second pulses of $30 \mathrm{nmol}$ $\mathrm{Ca}^{2+} / \mathrm{mg}$ protein led to a rapid depolarization followed by an almost complete reestablishment of $\Delta \Psi_{\mathrm{m}}$ (repolarization). However, a third pulse of $10 \mathrm{nmol} \mathrm{Ca}{ }^{2+} / \mathrm{mg}$ protein led to an irreversible loss of $\Delta \Psi_{\mathrm{m}}$ this effect being slowed (delayed) in mitochondria isolated from TAM animals. The presence of E2 did not affect significantly the effect of $\mathrm{Ca}^{2+}$ in all conditions tested (data not shown).

Table 2

Effect of E2 on oxidative phosphorylation parameters of mitochondria isolated from control, OVX and TAM-treated OVX females

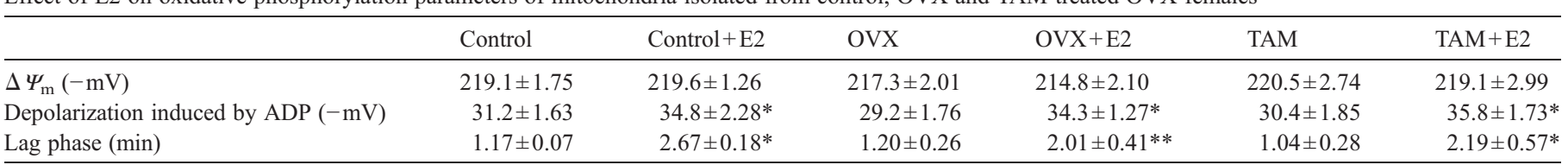

The values are expressed as mean \pm S.E.M of five to six animals. ${ }^{* *} p<0.01 ;{ }^{*} p<0.05$ when compared with control females. 


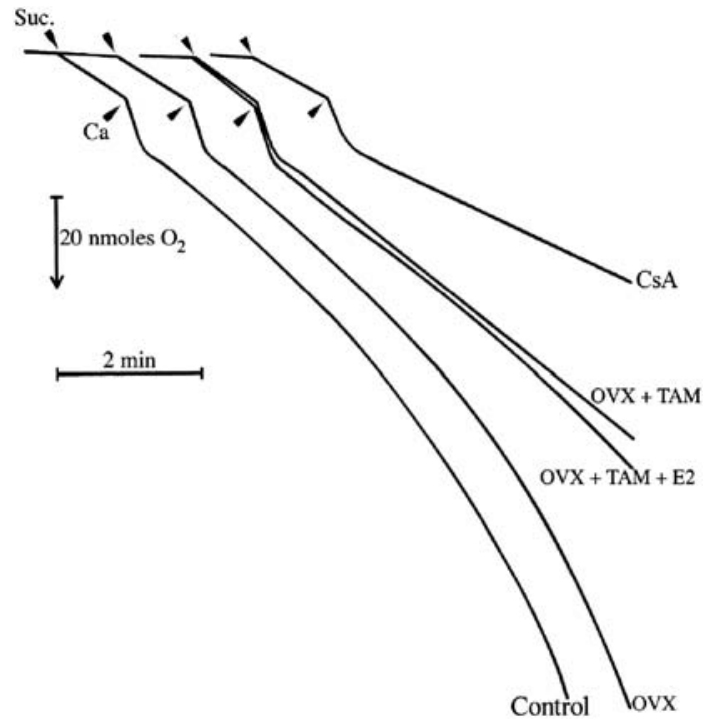

Fig. 2. Effect of $17 \beta$-estradiol (E2) on $\mathrm{Ca}^{2+}$-induced oxygen consumption of mitochondria isolated from control, ovariectomized (OVX) and tamoxifentreated ovariectomized $(\mathrm{OVX}+\mathrm{TAM})$ rat females. Freshly isolated liver mitochondria $(1 \mathrm{mg})$ in $1 \mathrm{ml}$ of the standard medium were energized with $5 \mathrm{mM}$ succinate (succ). Isolates from TAM females were incubated with E2 for $1 \mathrm{~min}$, at $30{ }^{\circ} \mathrm{C}$, before mitochondria energization. Cyclosporin A (CsA) $(0.85 \mu \mathrm{M})$ was added to the reaction medium $2 \mathrm{~min}$ prior to $\mathrm{Ca}^{2+}(70 \mathrm{nmol} / \mathrm{mg}$ protein) addition. The traces are typical of six experiments.

\section{E2 protects against lipid peroxidation}

Oxygen consumption and TBARS levels were used to determine the extension of lipid peroxidation (PX) induced by $\mathrm{ADP} / \mathrm{Fe}^{2+}$. We observed that maximal oxygen consumption occurs first in OVX (Fig. 4B) followed by TAM (Fig. 4C) and, finally, control (Fig. 4A) females. However, after $10 \mathrm{~min}$ there is

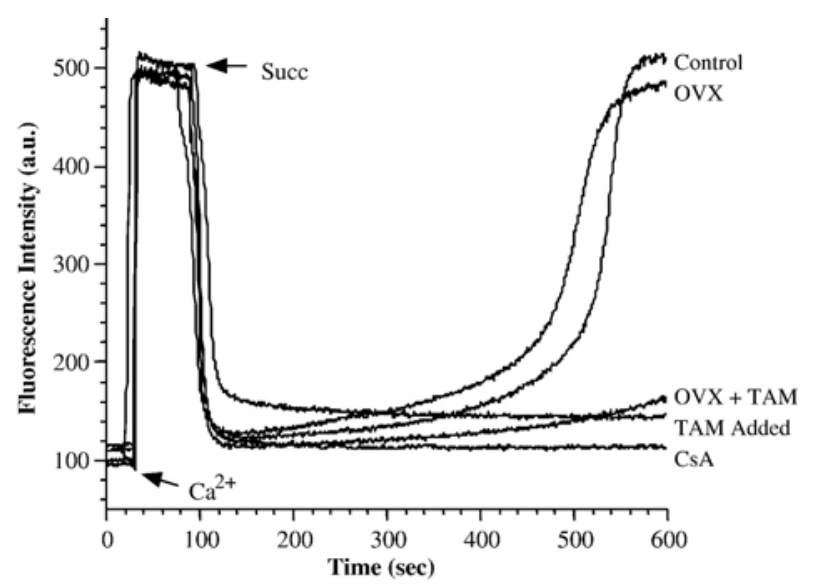

Fig. 3. Effect of tamoxifen (TAM) on $\mathrm{Ca}^{2+}$ fluxes of mitochondria isolated from control, ovariectomized (OVX) and tamoxifen-treated ovariectomized (OVX+ TAM) rat females. Freshly isolated liver mitochondria were incubated at $0.25 \mathrm{mg} / \mathrm{ml}$ under standard conditions as described in the Methods section. Standard medium was supplemented with $70 \mathrm{nmol} \mathrm{Ca}^{2+} / \mathrm{mg}$ protein $1 \mathrm{~min}$ before mitochondria energization with $5 \mathrm{mM}$ succinate (succ). Cyclosporin A (CsA) $(0.85 \mu \mathrm{M})$ or TAM were added to the reaction medium 2 min prior to $\mathrm{Ca}^{2+}$ addition. The traces are typical of six experiments.
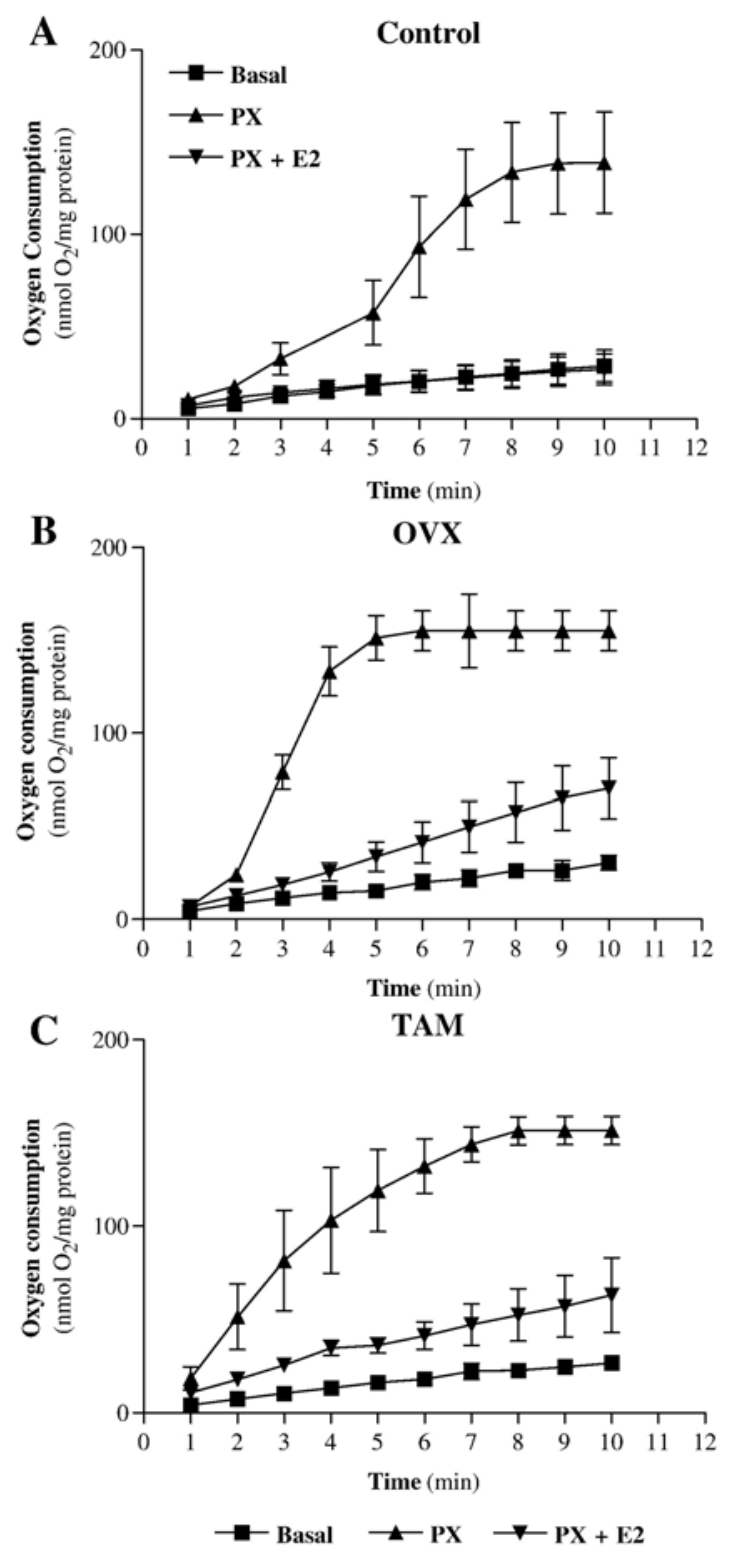

Fig. 4. Effect of $17 \beta$-estradiol (E2) on oxygen consumption induced by lipid peroxidation (Px). Mitochondria isolated from control, ovariectomized (OVX) and tamoxifen-treated ovariectomized (TAM) rat females were incubated at $1 \mathrm{mg} / \mathrm{ml}$ under standard conditions as described in the Methods section. Isolates were pre-incubated with $\mathrm{E} 2(\mathrm{PX}+\mathrm{E} 2)$ for $1 \mathrm{~min}$, at $30^{\circ} \mathrm{C}$, before the addition of $\mathrm{ADP} / \mathrm{Fe}^{2+}(\mathrm{PX})$. Data shown represent mean \pm S.E.M. from six animals for each experimental group studied.

no statistical difference in the levels of oxygen consumption when the three groups of females were compared. However, the presence of E2 decreased significantly the effects of ADP/ $/ \mathrm{Fe}^{2+}$ in the three groups of animals and, in control females these levels are similar to those at basal conditions (Fig. 4). Accordingly, after $10 \mathrm{~min}$ of PX the levels of TBARS are similar in the three groups of animals studied (Fig. 5). The presence of E2 decreased significantly those levels this effect being more pronounced in control females where the levels of TBARS induced by $\mathrm{ADP} / \mathrm{Fe}^{2+}$ are similar to the levels occurring at basal conditions (Fig. 5). 


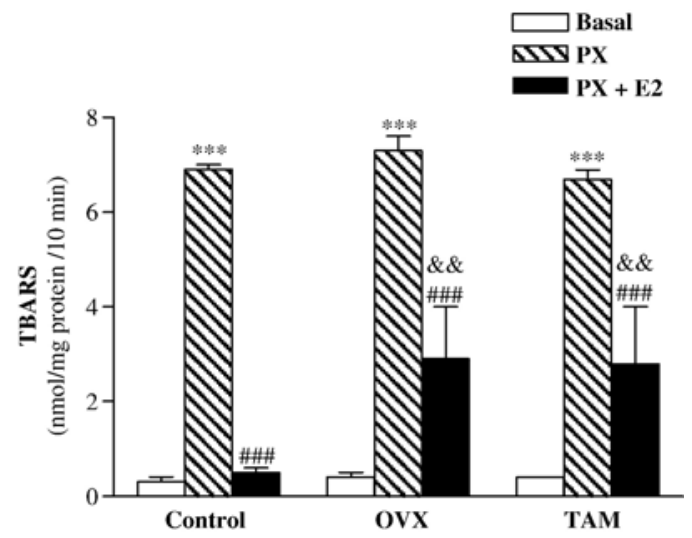

Fig. 5. Effect of 17ß-estradiol (E2) on TBARS levels. Mitochondria isolated from control, ovariectomized (OVX) and tamoxifen-treated ovariectomized (TAM) rat females were incubated at $1 \mathrm{mg} / \mathrm{ml}$ under standard conditions as described in the Methods section. Isolates were pre-incubated with E2 $(\mathrm{PX}+\mathrm{E} 2)$ for $1 \mathrm{~min}$, at $30^{\circ} \mathrm{C}$, before the addition of $\mathrm{ADP} / \mathrm{Fe}^{2+}$ (PX). Data shown represent mean \pm S.E.M. from six animals for each experimental group studied. $* * * p<0.001, * * p<0.01$ when compared with the respective basal condition. $\# \# p<0.001$ when compared with PX condition.

\section{E2 increases the production of $\mathrm{H}_{2} \mathrm{O}_{2}$ in energized mitochondria of control females}

In the absence of substrate the capacity of mitochondria to produce $\mathrm{H}_{2} \mathrm{O}_{2}$ in the presence/absence of E2 is similar in the three groups of animals studied (Fig. 6). Although energized mitochondria, at basal conditions, produce higher levels of $\mathrm{H}_{2} \mathrm{O}_{2}$, that increase was not statistically significant. However, the presence of E2 induced a significant increase in $\mathrm{H}_{2} \mathrm{O}_{2}$ production in energized mitochondria of control females.

\section{Discussion}

This study shows that E2, despite its protector effect against lipid peroxidation, affects profoundly liver mitochondrial function which is not consistent with the bulk of the literature focussing the effects of E2 (Lu et al., 2007; Nilsen et al., 2006). Furthermore, we observed that TAM-treatment per se delay PTP opening supporting previous data from the literature (Custodio et al., 1998; Moreira et al., 2005). Furthermore, our study also shows that TAM treatment and ovariectomy induce alterations in biochemical parameters as well as in body weight.

We observed that ovariectomy induces a body weight gain while TAM treatment avoids body weight gain (Table 1). It has been shown that menopause is associated with a decrease in the resting metabolic rate that reduces the utilization of calories and hence increases body weight (van Seumeren, 2000). Furthermore, previous studies also reported that treatment of ovariectomized rats with TAM mimics the effects of E2 and causes significant decreases in food intake and body weight (Wade and Heller, 1993). The decreases in body weight are reflected mainly in a decreased body fat content and, similar to the effects of E2, TAM decreases parametrial white adipose tissue wet weight and lipoprotein lipase activity (Wade and Heller, 1993). Recently, Lopez and collaborators (2006) reported that the anorectic effect of TAM is associated with the accumulation of malonyl-CoA in the hypothalamus and inhibition of fatty acid synthase expression specifically in the ventromedial nucleus of the hypothalamus.

Approximately $40 \%$ of total cholesterol removal occurs by conversion to bile acids, a process that takes place in the liver. Recently, Czerny et al. (2005) reported that ovariectomy causes decreased excretion of bile and bile acids. Furthermore, they reported that TAM and raloxifene administration do not reverse the changes in bile composition induced by estrogen deficiency. We also observed that ovariectomy increases total and HDL cholesterol but, in this study, TAM treatment reversed these effects (Table 1). Furthermore, the effects of raloxifene on lipids and lipoproteins in 2659 women with either normal or high triglyceride levels have been studied (Dayspring et al., 2006). In both triglyceride subgroups, raloxifene significantly improved low-density lipoprotein cholesterol, total cholesterol, non-highdensity lipoprotein cholesterol (HDL-C), apolipoprotein B, apolipoprotein A-I, and fibrinogen compared with placebo (Dayspring et al., 2006). Recently, Liu et al. (2006) investigated the changes in serum aspartate aminotransferase and alanine aminotransferase levels in patients with breast cancer treated with TAM. They observed that 115 patients had elevations of aspartate aminotransferase, alanine aminotransferase or both, although the magnitude of the elevation was clinically significant only in 32 patients. Furthermore, El-Beshbishy (2005) showed that TAM induces increases in serum glutamate pyruvate transaminase and serum glutamate oxaloacetate transaminase in rat females. Accordingly, we also observed that TAM treatment alters transaminases (Table 1), which is an expected result since TAM is extensively metabolized in the liver (Fromson et al., 1973).

Mitochondria are organelles essential for generating energy that fuels normal cellular function and, at the same time, are the major intracellular source of cytotoxic free radicals and the primary determinants of cell death (Green and Kroemer, 2004). The unique role of the mitochondria is in supplying high-energy ATP molecules, while at the same time, monitoring cellular

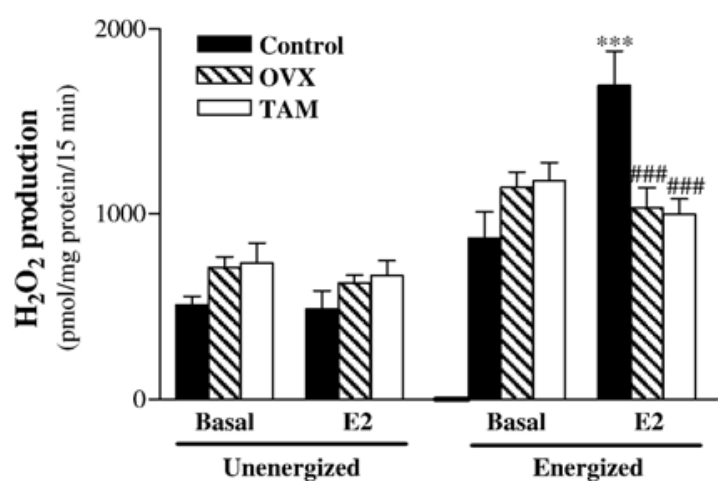

Fig. 6. Effect of $17 \beta$-estradiol (E2) on mitochondrial $\mathrm{H}_{2} \mathrm{O}_{2}$ production. Freshly isolated liver mitochondria were incubated at $0.2 \mathrm{mg} / \mathrm{ml}$ under standard conditions as described in the Methods section. Data shown represent mean \pm S.E.M. from six animals for each experimental group studied. $* * * p<0.001$ when compared with the energized basal condition. \#\#\#p<0.001 when compared with energized control condition in the presence of E2. 
health in order to make a rapid decision to initiate a programmed cell death. As such, mitochondria sit at a strategic position in the hierarchy of cellular organelles to continue the healthy life of the cell or to terminate it.

We observed that at basal conditions neither ovariectomy nor TAM treatment induce any significant alteration on mitochondrial respiratory parameters (Fig. 1). However, we observed that the respiratory chain is profoundly affected by E2 this effect being more evident in TAM treated females (Fig. 1). Although E2 acts as a partial uncoupler (Fig. 1B) it is more an inhibitor of respiration than an uncoupler because it does not inhibit the uncoupling effect of FCCP (Fig. 1D). We also observed that E2 impairs the oxidative phosphorylation system (Table 2). These data are supported by a previous in vitro study from our laboratory that showed that lower concentrations of TAM that do not interfere with mitochondrial function, in the presence of E2 significantly affect the function of these organelles. Furthermore, we were able to show that TAM and E2 act directly on the flavin mononucleotide (FMN) site of complex I leading to mitochondrial failure (Moreira et al., 2006). Although these results were obtained with liver mitochondria isolated from male rats, preliminary results from our laboratory show the same effects in mitochondria isolated from female rats though less pronounced. Differences between genders are supported by previous studies that showed that mitochondria from females suffer less oxidative damage in critical biomolecules such as mitochondrial DNA and glutathione as compared with males (Borras et al., 2003; Vina et al., 2003). Indeed, the authors reported that levels of 8-oxodeoxyguanosine, a marker of DNA oxidative damage, are four times greater in mitochondria from males than in females while mitochondrial GSH levels are double in females than in males. In addition, it has been shown that brain and liver mitochondria isolated from female rats and mice produce approximately half the amount of $\mathrm{H}_{2} \mathrm{O}_{2}$ generated by mitochondria isolated from males (Borras et al., 2003).

At this point it is important to note that although estrogen synthesis occurs in the mitochondria, exogenously added estrogen is also transported to this organelle. For instance, in vivo exposure of ovariectomized rats to tritiated $\mathrm{E} 2$ showed with increasing time, the translocation of this hormone from the plasmalemma mainly to the mitochondria $(75 \%)$ rather than the nuclei in liver, adrenal gland, and spleen tissues (Moats and Ramirez, 1998). The lipophilic property of E2 allows this molecule to easily diffuse into lipid bilayers. Since mitochondria are enriched with lipids, the organelle has the ability to act as an estrogen-sink within cell.

In this study, we observed that TAM treatment increases mitochondrial $\mathrm{Ca}^{2+}$ uptake delaying PTP induction (Figs. 3 and 4). The PTP causes a non-selective permeabilization of the inner mitochondrial membrane typically promoted by the accumulation of excessive quantities of $\mathrm{Ca}^{2+}$ ions and stimulated by a variety of compounds or conditions (Zoratti and Szabo, 1995). In this study, the classic inductor $\mathrm{Ca}^{2+}$ was used to induce PTP opening (Figs. 2 and 3). Accordingly, previous in vitro studies also indicate that TAM (Custodio et al., 1998; Moreira et al., 2005) and OHTAM (Cardoso et al., 2002; Moreira et al., 2004) are potent inhibitors of PTP induction in liver and brain mito- chondria. However, we observed that E2 exposure does not interfere with $\mathrm{Ca}^{2+}$ influx (Fig. 2). Previously, Petrovic and collaborators (2005) observed that in vitro E2 exposure does not interfere on $\mathrm{Ca}^{2+}$ influx through ruthenium red-sensitive channels in synaptosomal mitochondria of chronically ovariectomized female rats.

In contrast with the other parameters analyzed in this study, PTP experiments were done with succinate, a substrate of mitochondrial complex II. From the bioenergetics point of view, the choice of succinate as substrate tends to provide the most consistent results because succinate oxidation does not require matrix pyridine nucleotides, which can be lost via the PTP during storage or incubation even when swelling is undetectable (Vinogradov et al., 1972). Furthermore, our previous in vitro study with liver mitochondria isolated from male rats (Moreira et al., 2006) as well as our preliminary results obtained from female rats show that E2 affects mitochondrial complex I. To avoid interferences in $\mathrm{Ca}^{2+}$ fluxes induced by $\mathrm{E} 2$ on mitochondrial complex I, we used succinate as mitochondrial substrate.

We observed that lipid peroxidation occurs faster in mitochondria isolated from OVX females (Fig. 4B) when compared with TAM (Fig. 4C) and control (Fig. 4A) females. Besides their chemopreventing function, TAM and OHTAM, which are extremely lipophilic (Custodio et al., 1991, 1993), induce multiple cellular effects, including antioxidant actions since they are strong intramembranous scavengers of peroxyl radicals (Custodio et al., 1994). The presence of E2 exerted a significant protection against $\mathrm{ADP} / \mathrm{Fe}^{2+}$-induced lipid peroxidation (Figs. 4A, B, C and 5). Accordingly, recent studies have shown that although ovariectomy leads to oxidative damage in liver (Oztekin et al., 2006a) and renal tissue (Oztekin et al., 2006b), female sex hormones (E2 and progesterone) supplementation protect against lipid peroxidation by activating the antioxidant system. In the same line, it has been shown that postmenopausal women tend to have high levels of plasma malondialdehyde (MDA) that are reversed by estrogen replacement therapy (Kumru et al., 2005). Similarly, Wang and collaborators (2006) using human neuroblastoma SK-N-SH cells as experimental model, reported that $\mathrm{E} 2$ effectively reduce lipid peroxidation induced by $5-\min _{2} \mathrm{H}_{2} \mathrm{O}_{2}$ exposure. Moreover, the authors observed that the estrogen receptor antagonist fulvestrant (ICI 182,780) did not block the effects of E2 (Wang et al., 2006) supporting previous findings from our laboratory indicating that the effects of E2 on liver mitochondria are estrogen-receptor independent (Moreira et al., 2006). Although we observed that E2 exerts a strong protective effect against lipid peroxidation (Figs. 4 and 5) it also induces a significant increase in $\mathrm{H}_{2} \mathrm{O}_{2}$ production in energized mitochondria of control females (Fig. 6). To clarify this apparent paradox, we measured the basal activities of manganese superoxide dismutase (MnSOD) and glutathione peroxidase (GPx), two important enzymes that detoxify ROS. The detoxification of superoxide $\left(\mathrm{O}_{2}^{-}\right)$is a two-stage reaction involving, in a first step, SOD that catalyzes the reduction of $\mathrm{O}_{2}^{--}$to $\mathrm{H}_{2} \mathrm{O}_{2}$, itself a very damaging reactive molecule via the Fenton reaction and, in the second stage involves the reduction of $\mathrm{H}_{2} \mathrm{O}_{2}$ to $\mathrm{H}_{2} \mathrm{O}$ by GPx. 
Although not statistically significant, we observed a slight decrease in the activity of MnSOD while GPx activity is slightly increased in control rats when compared with ovariectomized and tamoxifen-treated ovariectomized female rats (data not shown). In accordance we observed a slightly reduced production of $\mathrm{H}_{2} \mathrm{O}_{2}$ in unenergized (presence/absence of E2) and energized (absence of E2) mitochondria of control females when compared with ovariectomized and TAM-treated ovariectomized females (Fig. 6). By contrast, in the presence of E2 the levels of $\mathrm{H}_{2} \mathrm{O}_{2}$ produced by energized mitochondria of control females increases significantly (Fig. 6). However, previous studies showed that GPx is important not only in the detoxification of $\mathrm{H}_{2} \mathrm{O}_{2}$ but also participates in the detoxification of lipid hydroperoxides using glutathione in this process (McCray et al., 1979), which is in accordance with our lipid peroxidation results (Figs. 4 and 5). Furthermore, it has been reported that GPx is involved in redox sensing pathways and redox regulation of metabolic events (Brigelius-Flohe, 2006). Little is known about the protective signalling cascades that are activated by oxidative stress under normal metabolic conditions. These signalling pathways are activated by mitochondrial or cytoplasmic proteins that detect an increase in ROS and lead to the increased expression of genes encoding proteins responsible for cellular and mitochondrial detoxification (Storz, 2006). $\mathrm{H}_{2} \mathrm{O}_{2}$ is a small and uncharged molecule that can freely diffuse through cellular membranes and represents an unquestionable long-range second messenger signalling (Finkel, 2003). There is evidence that $\mathrm{H}_{2} \mathrm{O}_{2}$ can activate many components of intracellular signalling cascades that are involved in cell survival, proliferation, differentiation and cell death (Boyd and Cadenas, 2002). Recently, it has been shown that rapid E2-induced changes in mitochondrial ROS production and mitochondrial $\mathrm{Ca}^{2+}$ are involved in cell cycle progression presumably through the control of early cell cycle genes (Parkash et al., 2006).

Overall our results indicate that, in general, exogenous E2 modulates negatively mitochondria suggesting that HRT should be considered carefully. However, more studies will be useful in resolving the controversy about the risks versus benefits of E2 supplementation.

\section{References}

Barja, G., 1999. Mitochondrial oxygen radical generation and leak: sites of production in states 4 and 3, organ specificity, and relation to aging and longevity. J. Bioenerg. Biomembr. 31, 347-366.

Borras, C., Sastre, J., Garcia-Sala, D., Lloret, A., Pallardo, F.V., Vina, J., 2003. Mitochondria from females exhibit higher antioxidant gene expression and lower oxidative damage than males. Free Radical Biol. Med. 34, 546-552.

Brigelius-Flohe, R., 2006. Glutathione peroxidases and redox-regulated transcription factors. Biol. Chem. 387, 1329-1335.

Boyd, C.S., Cadenas, E., 2002. Nitric oxide and cell signaling pathways in mitochondrial-dependent apoptosis. Biol. Chem. 383, 411-423.

Cardoso, C.M., Almeida, L.M., Custodio, J.B., 2002. 4-Hydroxytamoxifen is a potent inhibitor of the mitochondrial permeability transition. Mitochondrion $1,485-495$.

Chance, B., Williams, G.R., 1956. Respiratory enzymes in oxidative phosphorylation. VI. The effects of adenosine diphosphate on azide-treated mitochondria. J. Biol. Chem. 221, 477-489.
Custodio, J.B., Almeida, L.M., Madeira, V.M., 1991. A reliable and rapid procedure to estimate drug partitioning in biomembranes. Biochem. Biophys. Res. Commun. 176, 1079-1085.

Custodio, J.B., Almeida, L.M., Madeira, V.M., 1993. The active metabolite hydroxytamoxifen of the anticancer drug tamoxifen induces structural changes in membranes. Biochim. Biophys. Acta 1153, 308-314.

Custodio, J.B., Dinis, T.C., Almeida, L.M., Madeira, V.M., 1994. Tamoxifen and hydroxytamoxifen as intramembraneous inhibitors of lipid peroxidation. Evidence for peroxyl radical scavenging activity. Biochem. Pharmacol. 47, 1989-1998.

Custodio, J.B., Moreno, A.J., Wallace, K.B., 1998. Tamoxifen inhibits induction of the mitochondrial permeability transition by $\mathrm{Ca}^{2+}$ and inorganic phosphate. Toxicol. Appl. Pharmacol. 152, 10-17.

Czerny, B., Pawlik, A., Teister, M., Juzyszyn, Z., Mysliwiec, Z., 2005. Effect of tamoxifen and raloxifene on cholesterol transformation to bile acids in ovariectomized rats. Gynecol. Endocrinol. 20, 313-316.

Dayspring, T., Qu, Y., Keech, C., 2006. Effects of raloxifene on lipid and lipoprotein levels in postmenopausal osteoporotic women with and without hypertriglyceridemia. Metabolism 55, 972-979.

Duchen, M.R., 2004. Mitochondria in health and disease; perspectives on a new mitochondrial biology. Mol. Aspects Med. 25, 365-451.

El-Beshbishy, H.A., 2005. Hepatoprotective effect of green tea (Camellia sinensis) extract against tamoxifen-induced liver injury in rats. J. Biochem. Mol. Biol. 38, 563-570.

Estabrook, R.E., 1967. Mitochondrial respiratory control and the polarographic measurement of ADP/O ratios. Methods Enzymol. 10, 41-47.

Felty, Q., Roy, D., 2005. Estrogen, mitochondria, and growth of cancer and noncancer cells. J. Carcinog. 4, 1.

Finkel, T., 2003. Oxidant signals and oxidative stress. Curr. Opin. Cell Biol. 15, $247-254$.

Fromson, J.M., Pearson, S., Bramah, S., 1973. The metabolism of tamoxifen (I C.I. 46,474): II. In female patients. Xenobiotica 3, 711-714.

Gazotti, P., Malmstron, K., Crompton, M., 1979. A Laboratory Manual on Transport and Bioenergetics. Springer Verlag, New York.

Gornall, A.G., Bardawill, C.J., David, M.M., 1949. Determination of serum proteins by means of the biuret reaction. J. Biol. Chem. 177, 751-766.

Green, D.R., Kroemer, G., 2004. The pathophysiology of mitochondrial cell death. Science 305, 626-629.

Kamo, N., Muratsugu, M., Hongoh, R., Kobatake, Y., 1979. Membrane potential of mitochondria measured with an electrode sensitive to tetraphenyl phosphonium and relationship between proton electrochemical potential and phosphorylation potential in steady state. J. Membr. Biol. 49, $105-121$.

Katzenellenbogen, J.A., O’Malley, B.W., Katzenellenbogen, B.S., 1996. Tripartite steroid hormone receptor pharmacology: interaction with multiple effector sites as a basis for the cell- and promoter-specific action of these hormones. Mol. Endocrinol. 10, 119-131.

Kumru, S., Aydin, S., Aras, A., Gursu, M.F., Gulcu, F., 2005. Effects of surgical menopause and estrogen replacement therapy on serum paraoxonase activity and plasma malondialdehyde concentration. Gynecol. Obstet. Invest. 59, $108-112$.

Kwan, K., Ward, C., Marsden, J., 2005. Is there a role for hormone replacement therapy after breast cancer? J. Br. Menopause Soc. 11, 140-144.

Lim, Y.C., Li, L., Desta, Z., Zhao, Q., Rae, J.M., Flockhart, D.A., Skaar, T.C., 2006. Endoxifen, a secondary metabolite of tamoxifen, and 4-OH-tamoxifen induce similar changes in global gene expression patterns in MCF-7 breast cancer cells. J. Pharmacol. Exp. Ther. 318, 503-512.

Liu, C.L., Huang, J.K., Cheng, S.P., Chang, Y.C., Liu, J.J., 2006. Fatty liver and transaminase changes with adjuvant tamoxifen therapy. Anti-cancer Drugs $17,709-713$.

Lopez, M., Lelliott, C.J., Tovar, S., Kimber, W., Gallego, R., Virtue, S., Blount, M., Vazquez, M.J., Finer, N., Powles, T.J., O’Rahilly, S., Saha, A.K., Dieguez, C., Vidal-Puig, A.J., 2006. Tamoxifen-induced anorexia is associated with fatty acid synthase inhibition in the ventromedial nucleus of the hypothalamus and accumulation of malonyl-CoA. Diabetes 55, $1327-1336$

Lu, A., Frink, M., Choudhry, M.A., Hubbard, W.J., Rue III, L.W., Bland, K.I., Chaudry, I.H., 2007. Mitochondria play an important role in 17b-estradiol 
attenuation of $\mathrm{H}_{2} \mathrm{O}_{2}$-induced endothelial cell apoptosis. Am. J. Physiol. Endocrinol. Metab. 292, E585-E593.

McCray, P.B., Gibson, D.D., Fong, K.L., Hornbrook, K.R., 1979. Effect of glutathione peroxidase activity on lipid peroxidation in biological membranes. Biochim. Biophys. Acta 431, 459-468.

McDonnell, D.P., 2000. Selective estrogen receptor modulators (SERMs): A first step in the development of perfect hormone replacement therapy regimen. J. Soc. Gynecol. Investig. 7, S10-S15.

Moats II, R.K., Ramirez, V.D., 1998. Rapid uptake and binding of estradiol17beta-6-(O-carboxymethyl)oxime:125I-labeled BSA by female rat liver. Biol. Reprod. 58, 531-538.

Moreira, P.I., Custodio, J.B., Oliveira, C.R., Santos, M.S., 2004. Hydroxytamoxifen protects against oxidative stress in brain mitochondria. Biochem. Pharmacol. 68, 195-204.

Moreira, P.I., Custodio, J.B., Oliveira, C.R., Santos, M.S., 2005. Brain mitochondrial injury induced by oxidative stress-related events is prevented by tamoxifen. Neuropharmacology 48, 435-447.

Moreira, P.I., Custodio, J., Moreno, A., Oliveira, C.R., Santos, M.S., 2006. Tamoxifen and estradiol interact with the flavin mononucleotide site of complex I leading to mitochondrial failure. J. Biol. Chem. 281, $10143-10152$.

Muratsugu, M., Kamo, N., Kurihara, K., Kobatake, Y., 1977. Selective electrode for dibenzyl dimethyl ammonium cation as indicator of the membrane potential in biological systems. Biochim. Biophys. Acta 464, 613-619.

Nilsen, J., Chen, S., Irwin, R.W., Iwamoto, S., Brinton, R.D., 2006. Estrogen protects neuronal cells from amyloid beta-induced apoptosis via regulation of mitochondrial proteins and function. BMC Neurosci. 7, 74.

Oztekin, E., Tiftik, A.M., Baltaci, A.K., Mogulkoc, R., 2006a. Lipid peroxidation in liver tissue of ovariectomized and pinealectomized rats: effect of estradiol and progesterone supplementation. Cell Biochem. Funct., doi:10.1002/cbf.1313.

Oztekin, E., Baltaci, A.K., Tiftik, A.M., Mogulkoc, R., 2006b. Lipid peroxidation in ovariectomized and pinealectomized rats: the effects of estradiol and progesterone supplementation. Cell Biochem. Funct., doi:10.1002/cbf.1360.

Parkash, J., Felty, Q., Roy, D., 2006. Estrogen exerts a spatial and temporal influence on reactive oxygen species generation that precedes calcium uptake in high-capacity mitochondria: implications for rapid nongenomic signaling of cell growth. Biochemistry 45, 2872-2881.

Petrovic, S., Demajo, M., Horvat, A., 2005. Estradiol affects calcium transport across mitochondrial membrane in different brain regions. Ann. N. Y. Acad. Sci. 1048, 341-343.

Rajdev, S., Reynolds, I.J., 1993. Calcium green-5N, a novel fluorescent probe for monitoring high intracellular free $\mathrm{Ca} 2+$ concentrations associated with glutamate excitotoxicity in cultured rat brain neurons. Neurosci. Lett. 162, $149-152$.

Richardson, D.N., 1988. The history of Nolvadex. Drug Des. Delivery 3, 1-14. Santos, M.S., Santos, D.L., Palmeira, C.M., Seiça, R., Moreno, A.J., Oliveira, C.R., 2001. Brain and liver mitochondria isolated from diabetic GotoKakizaki rats show different susceptibility to induced oxidative stress Diabetes Metab. Res. Rev. 17, 223-230.

Sato, M., Rippy, M.K., Bryant, H.U., 1996. Raloxifene, tamoxifen, nafoxidine, or estrogen effects on reproductive and nonreproductive tissues in ovariectomized rats. FASEB J. 10, 905-912.

van Seumeren, I.V., 2000. Weight gain and hormone replacement therapy: are women's fears justified? Maturitas 34, S3-S8.

Storz, P., 2006. Reactive oxygen species-mediated mitochondria-to-nucleus signaling: a key to aging and radical-caused diseases. Sci. STKE re3.

Tsuchiya, Y., Nakajima, M., Yokoi, T., 2005. Cytochrome P450-mediated metabolism of estrogens and its regulation in human. Cancer Lett. 227, 115-124.

Vina, J., Sastre, J., Pallardo, F., Borras, C., 2003. Mitochondrial theory of aging: importance to explain why females live longer than males. Antioxid. Redox Signal. 5, 549-556.

Vinogradov, A., Scarpa, A., Chance, B., 1972. Calcium and pyridine nucleotide interaction in mitochondrial membranes. Arch. Biochem. Biophys. 152, 646-654.

Wade, G.N., Heller, H.W., 1993. Tamoxifen mimics the effects of estradiol on food intake, body weight, and body composition in rats. Am. J. Physiol. 264, R1219-R1223.

Wallace, K.B., Starkov, A.A., 2000. Mitochondrial targets of drug toxicity. Annu. Rev. Pharmacol. Toxicol. 40, 353-388.

Wingrove, D.E., Gunter, T.E., 1986. Kinetics of mitochondrial calcium transport. II. A kinetic description of the sodium-dependent calcium efflux mechanism of liver mitochondria and inhibition by ruthenium red and by tetraphenylphosphonium. J. Biol. Chem. 261, 15166-15171.

Wang, X., Dykens, J.A., Perez, E., Liu, R., Yang, S., Covey, D.F., Simpkins, J.W., 2006. Neuroprotective effects of 17 beta-estradiol and nonfeminizing estrogens against $\mathrm{H}_{2} \mathrm{O}_{2}$ toxicity in human neuroblastoma SK-N-SH cells. Mol. Pharmacol. 70, 395-404.

Yang, S.H., Liu, R., Perez, E.J., Wen, Y., Stevens Jr., S.M., Valencia, T., BrunZinkernagel, A.M., Prokai, L., Will, Y., Dykens, J., Koulen, P., Simpkins, J., 2004. Mitochondrial localization of estrogen receptor beta. Proc. Natl. Acad. Sci. U.S.A. 101, 4130-4135.

Zheng, J., Ramirez, V.D., 1999. Purification and identification of an estrogen binding protein from rat brain: oligomycin sensitivity-conferring protein (OSCP), a subunit of mitochondrial F0F1-ATP synthase/ATPase. J. Steroid. Biochem. Mol. Biol. 68, 65-75.

Zoratti, M., Szabo, I., 1995. The mitochondrial permeability transition. Biochim. Biophys. Acta 1241, 139-176. 